\title{
Potential for release of pulmonary toxic ketene from vaping pyrolysis of vitamin $E$ acetate
}

\author{
Dan Wu ${ }^{\mathrm{a}, 1}$ and Donal F. O'Shea ${ }^{\mathrm{a}, 1}$ (1) \\ aDepartment of Chemistry, Royal College of Surgeons in Ireland (RCSI), Dublin 2, Ireland
}

Edited by Scott H. Randell, The University of North Carolina at Chapel Hill, and accepted by Editorial Board Member Brigid L. Hogan February 11, 2020 (received for review December 3, 2019)

\begin{abstract}
A combined analytical, theoretical, and experimental study has shown that the vaping of vitamin $\mathrm{E}$ acetate has the potential to produce exceptionally toxic ketene gas, which may be a contributing factor to the upsurge in pulmonary injuries associated with using e-cigarette/ vaping products. Additionally, the pyrolysis of vitamin $\mathrm{E}$ acetate also produces carcinogen alkenes and benzene for which the negative longterm medical effects are well recognized. As temperatures reached in vaping devices can be equivalent to a laboratory pyrolysis apparatus, the potential for unexpected chemistries to take place on individual components within a vape mixture is high. Educational programs to inform of the danger are now required, as public perception has grown that vaping is not harmful.
\end{abstract}

vaping | pyrolysis | ketene | vitamin E acetate | lung injury

$T^{\mathrm{r}}$ he Centers for Disease Control and Prevention (CDC) and Food and Drug Administration have recently reported an increasing number of clinically reported cases of pulmonary injury following use of e-cigarette/vaping products (1). The cause(s) of this growing epidemic of vaping associated pulmonary injury remain unidentified, although studies in mice have shown that chronic exposure to e-cigarette vapor abnormally alters the physiology of lung epithelial cells with changes in lipid homeostasis being independent of nicotine (2). Vitamin E acetate $\mathbf{1}$ is used as an additive in some vaping products and was recently reported as one possible causative agent (Fig. 1). Results from a multicentered study have identified it in bronchoalveolar lavage fluid specimens from 48 of 51 patients examined (3). As the synthetic $O$-acetylated analog of vitamin E 2 , it is widely used in cosmetic skincare products and as a dietary supplement. The acetylated version of the vitamin is preferred due to its more facile purification during production, its increased formulation stability, and as ester hydrolysis in vivo generates vitamin $\mathrm{E}$ (4). As it is a viscous lipid oil, $\mathbf{1}$ is added to some vape mixtures, especially to those containing tetrahydrocannabinol and cannabidiol oils. These mixtures are growing in use for nonmedical recreational purposes, which appears to be closely linked to the current medical crisis (1).

In the first preliminary reports, lipid accumulation in the lungs as a result of vaping was proposed to play a role in causing exogenous lipoid pneumonia $(5,6)$. In a subsequent report of six patients suffering from vaping-associated lung injury, computed tomography scans did not show known features consistent with exogenous lipoid pneumonia (7). Most recently, pathology of 17 patients with vaping-associated lung injury revealed patterns more consistent with airway-centered chemical pneumonitis from inhaled toxic substance(s) rather than exogenous lipoid pneumonia (8). To date, the causative agent(s) remain unidentified and with so many parameters and variables involved, it appears unlikely that vitamin $\mathrm{E}$ acetate alone would have such acute and severe toxicity.

However, the chemical stability and reactivity of $\mathbf{1}$, under hightemperature pyrolysis conditions, has not been investigated. Critically, the temperature of heating coils within vaping devices is highly variable and has been measured to range between 110 and $1,008^{\circ} \mathrm{C}$. Several factors can contribute to the actual temperature(s) applied to the complex vape mixture, such as the heating coil resistance, voltage applied, composition of the mixture being vaporized, and the mode of user usage $(9,10)$. In reality, a vaping device should be considered as a crude uncontrollable minipyrolysis apparatus capable of causing changes to the chemical composition of a vaping mixture in an unpredictable manner. Specifically, the aryl acetate functional group present within $\mathbf{1}$ attracted our attention as a functional group sensitive to pyrolysis. The same functional group is present in phenyl acetate $\mathbf{3}$, the simplest aryl acetate, which is known to liberate the highly toxic gas ketene $\mathbf{4}$ under pyrolysis (Fig. 1). In this article, we describe our initial efforts to illustrate and highlight the potential of vitamin $\mathrm{E}$ acetate to release ketene under pyrolysis conditions, and that such conditions are achievable using a vaping device.

Pyrolysis of phenyl acetate $\mathbf{3}$ undergoes a thermal unimolecular elimination reaction to form phenol and ketene $\mathbf{4}$ at temperature of $625^{\circ} \mathrm{C}$, with ketene obtained in an $84 \%$ yield (Fig. 1) (11). This pyrolysis has been studied using electron ionization (EI) mass spectrometry to generate conditions to promote the elimination of ketene (12). Ketene is manufactured by pyrolysis of acetic acid at $700-800{ }^{\circ} \mathrm{C}$ and is used for synthetic acetylation reactions and for the production of bulk reagents (13). It is a colorless gas (boiling point $-56{ }^{\circ} \mathrm{C}$ ) with a penetrating odor above $12 \mathrm{ppm}$. Due to its extreme reactivity, the public extremely rarely encounters ketene, as when industrially produced it is not isolated but reacted in situ. However, it has very high pulmonary toxicity, and is lethal at high concentrations. At lower concentrations in animal studies, minor irritation during exposure and central nervous system impairment were observed $(14,15)$. It can acetylate nucleophilic components of proteins in aqueous solution and the pulmonary effects of

\section{Significance}

The Centers for Disease Control and Prevention has recently reported an increasing number of clinically cases of lung injury following use of vaping products. The cause(s) of this growing epidemic of vaping-associated pulmonary injury remain unidentified, although vitamin $\mathrm{E}$ acetate has been identified as one possible causative agent. In this research, a combined analytical, theoretical, and experimental study has shown that the vaping of vitamin $\mathrm{E}$ acetate has the potential to produce exceptionally toxic ketene gas, which may be a contributing factor to the upsurge in lung injuries associated with vaping products. Our important results will help inform medical practitioners, research scientists, and the public, which may assist in bringing this medical crisis under control.

Author contributions: D.F.O. designed research; D.W. and D.F.O. performed research; D.W. and D.F.O. analyzed data; and D.F.O. wrote the paper.

The authors declare no competing interest.

This article is a PNAS Direct Submission. S.H.R. is a guest editor invited by the Editorial Board. This open access article is distributed under Creative Commons Attribution-NonCommercialNoDerivatives License 4.0 (CC BY-NC-ND).

See online for related content such as Commentaries.

${ }^{1}$ To whom correspondence may be addressed. Email: donalfoshea@rcsi.ie or danwu@ rcsi.ie.

This article contains supporting information online at https://www.pnas.org/lookup/suppl/ doi:10.1073/pnas.1920925117/-/DCSupplemental.

First published March 10, 2020. 
<smiles>CC(=O)Oc1c(C)c(C)c2c(c1C)CCC(C)(CCCC(C)CCCC(C)CCCC(C)C)O2</smiles>

Vitamin $\mathrm{E}$ acetate<smiles>Cc1c(C)c2c(c(C)c1O)CCC(C)(CCCC(C)CCCC(C)CCCC(C)C)O2</smiles>

Vitamin E<smiles>CC(=O)Oc1ccccc1</smiles>

3

$$
\begin{gathered}
\mathrm{H}_{2} \mathrm{C}=\mathrm{C}=\mathrm{O} \\
\mathbf{4} \\
\text { Ketene }
\end{gathered}
$$

Phenyl acetate

Fig. 1. Chemical structures of vitamin E acetate 1, vitamin E 2, phenyl acetate $\mathbf{3}$, and ketene 4 .

inhalation exposure to $\mathbf{4}$ may be manifested in the absence of direct irritation by ketene. Severe damage to the lungs at the alveolar level may manifest as long as $24 \mathrm{~h}$ postexposure. Thus, it is unknown whether odor detection and minor irritation would provide adequate warning of ketene exposure, especially given the potential for delayed pulmonary toxicity. The toxicity of ketene has been assessed in various animal species and these studies indicate that it has similar clinical effect and mode of action as phosgene $\left(\mathrm{COCl}_{2}\right)(16)$. In toxicity studies with primates, the minimum lethal in-air concentration was determined to be $200 \mathrm{ppm}$, causing death after a single 10-min exposure (17).

As vitamin $\mathrm{E}$ acetate contains a similar acetate functional found in phenyl acetate, it appeared plausible to us that it too may produce ketene upon pyrolysis (Fig. 1). To investigate this possibility, a threefold investigation was adopted utilizing mass spectrometry, density-functional theory (DFT) calculations, and analysis of isolated products from vaped vitamin $\mathrm{E}$ acetate.

Mass Spectrometry Study. Phenyl acetate $\mathbf{3}$ was analyzed using atmospheric pressure chemical ionization (APCI) mass spectrometry (MS) at a series of increasing source cone voltages (CVs) from 5 to $30 \mathrm{eV}$. At $15 \mathrm{eV}$ the parent ion $[\mathrm{M}+\mathrm{H}]^{+}$was identifiable as the mass-to-charge ratio $(\mathrm{m} / \mathrm{z})$ of $137.1(10 \%)$ with fragmentation ion at $95.2(100 \%)$ (Fig. $2 A$ and SI Appendix, Fig. $\mathrm{S} 1)$. This corresponds with a mass loss of 42 from the parent ion, which is equivalent to ketene $\mathbf{4}$ and consistent with previous studies that used EI MS instrumentation (Fig. 3A) (12). An identical analysis of vitamin $\mathrm{E}$ acetate $\mathbf{1}$ also showed the elimination of ketene $(m / z=42)$ from the parent ion (as seen for 3 ) and from a fragment with $m / z$ of 207.2 (Fig. $2 B$ and SI Appendix, Fig. S2). A representative spectrum taken with $\mathrm{CV}$ of $20 \mathrm{eV}$ shown in Fig. $2 B$ reveals the parent ion $\mathrm{m} / \mathrm{z}$ of $473.6(100 \%)$ with fragmentation ions at $431.5(15 \%), 207.2(65 \%)$, and 165.2 being the most prominent features. Increasing the $\mathrm{CV}$ to $25 \mathrm{eV}$ decreased the abundance of the parent ion and increased the fragmentation such that $(\mathrm{m} / \mathrm{z})$ abundances were 473.6 (10\%), 431.5 (10\%), 207.2 (100\%), and 165.2 (10\%) (SI Appendix, Fig. S2). Clearly two fragmentation patterns can occur for $\mathbf{1}$ with fragmentation pattern A due to

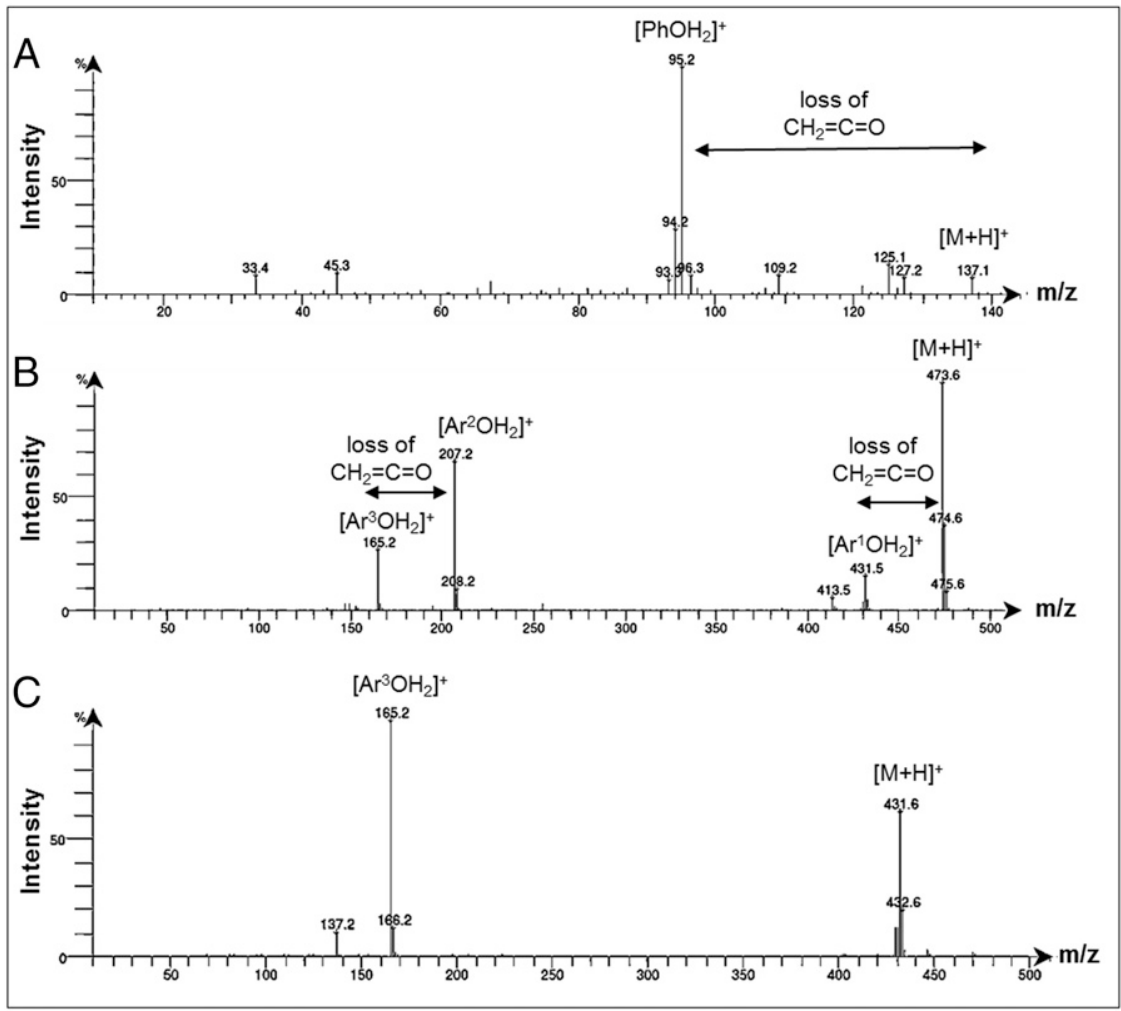

Fig. 2. Positive-mode APCI-MS of $(A)$ phenyl acetate 3 with source voltage of 15 eV showing loss of ketene; $(B)$ vitamin $E$ acetate 1 with source voltage of $20 \mathrm{eV}$ showing loss of ketene from both the parent ion and a fragmentation species of $\mathrm{m} / \mathrm{z} 207.2$; (C) vitamin E 2 with source voltage of 20 eV with sole fragmentation to $\left[\mathrm{Ar}^{3} \mathrm{OH}_{2}\right]^{+}$. 
A<smiles>CC(=O)Oc1ccccc1</smiles>

3

$\mathrm{C}_{8} \mathrm{H}_{8} \mathrm{O}_{2}$

Mol Wt: 136.15<smiles>Oc1ccccc1</smiles>

$\mathrm{C}_{6} \mathrm{H}_{6} \mathrm{O}$

Mol Wt: 94.11

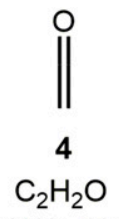

Mol Wt: 42.04

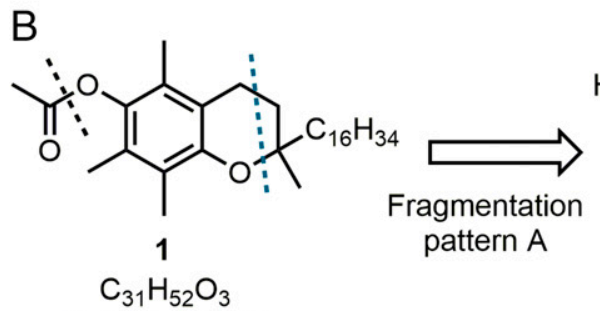

Mol Wt: 472.75

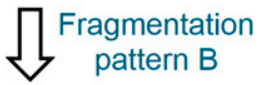

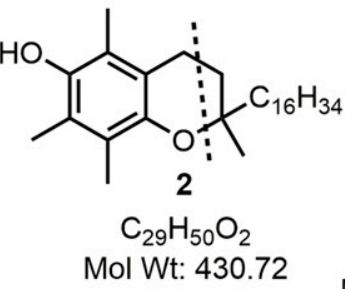

$\left[\mathrm{Ar}^{1} \mathrm{OH}_{2}\right]^{+}$<smiles>[C-]1C=CC=C1</smiles><smiles>C=C1C(=O)C(C)=C(C)C(OC(C)=O)=C1C</smiles><smiles>[3H]C(=C)c1ccccc1</smiles>

$\mathrm{C}_{19} \mathrm{H}_{38}$

6

Mol Wt: 266.51<smiles>[14CH3]O</smiles>

Mol Wt: 206.24

$\left[\mathrm{Ar}^{2} \mathrm{OH}_{2}\right]^{+}$ not observable

under MS

conditions<smiles>C=c1c(C)c(C)c(O)c(C)c1=C</smiles>

8<smiles>CCCO</smiles>

Mol Wt: 164.20

$\left[\mathrm{Ar}^{3} \mathrm{OH}_{2}\right]^{+}$

Fig. 3. APCI-MS fragmentation patterns of $A$ phenyl acetate 3 and $B$ vitamin $E$ acetate 1 each of which are observed as $+\mathrm{H}^{+}$masses in the mass spectra.

elimination of ketene $\mathbf{4}$ from the molecular ion producing vitamin E $2\left(\left[\mathrm{Ar}^{1} \mathrm{OH}_{2}\right]^{+}, m / z 431.5\right)$ whereas fragmentation pattern B has loss of prist-1-ene 7 producing $6\left(\left[\mathrm{Ar}^{2} \mathrm{OH}_{2}\right]^{+}, m / z 207.2\right)$ from which elimination of 4 generates $\left[\mathrm{Ar}^{3} \mathrm{OH}_{2}\right]^{+}(\mathrm{m} / \mathrm{z}$ 165.2) (Fig. $3 B)$. As a control, vitamin E 2 was also included in the MS study showing, as expected, no $\mathrm{m} / \mathrm{z}$ loss of 42 and showing the same $\left[\mathrm{Ar}^{3} \mathrm{OH}_{2}\right]^{+}(\mathrm{m} / \mathrm{z}$ 165.2) species observed as the lowest molecular weight fragment from 1 and attributable to structure 8 (Fig. 2C and SI Appendix, Fig. S3). As both $\mathbf{1}$ and $\mathbf{3}$ showed the same MS fragmentation pattern of ketene elimination, this provides the chemical basis by which the pyrolysis of vitamin $\mathrm{E}$ acetate would produce ketene.

As the APCI-MS for $\mathbf{1}$ and $\mathbf{3}$ both showed loss of ketene from the molecular ion but $\mathbf{1}$ also showed a loss from an intermediate fragment, we sought to further explore this possibility using DFT calculations. This would allow a direct comparison of activation energy barriers between the known ketene producer $\mathbf{1}$ and vitamin E acetate. The energy profiles and transition states (TS) for the elimination of ketene from $\mathbf{1 , 3}$ and $\mathbf{6}$ were calculated in the gas phase at the M06-2X/6-311G (d,p) level using the Gaussian 09 package (18).

DFT Theoretical Study. The elimination of ketene from $\mathbf{3}$ has been reported to proceed via four-membered TS with a concerted $[1,3]$ hydrogen shift from methyl to oxygen as shown in Fig. 4 $(19,20)$.

Gas-phase M06-2X/6-311G (d,p) calculations from 3 gave an activation energy of $65.4 \mathrm{kcal} / \mathrm{mol}$ via this pathway, confirming that it would be energetically feasible under pyrolysis conditions (Fig. 4, black energy profile). At this level of theory, the barrier for ketene elimination from 1 was only $4.1 \mathrm{kcal} / \mathrm{mol}$ higher than 3 at $69.5 \mathrm{kcal} / \mathrm{mol}$, indicating comparable pyrolysis reactivity for both (Fig. 4, blue energy profile). As the MS fragmentation data for 1 indicated ketene elimination from fragment $\mathbf{6}$ can also occur, its energy barrier to release ketene was calculated and found to be

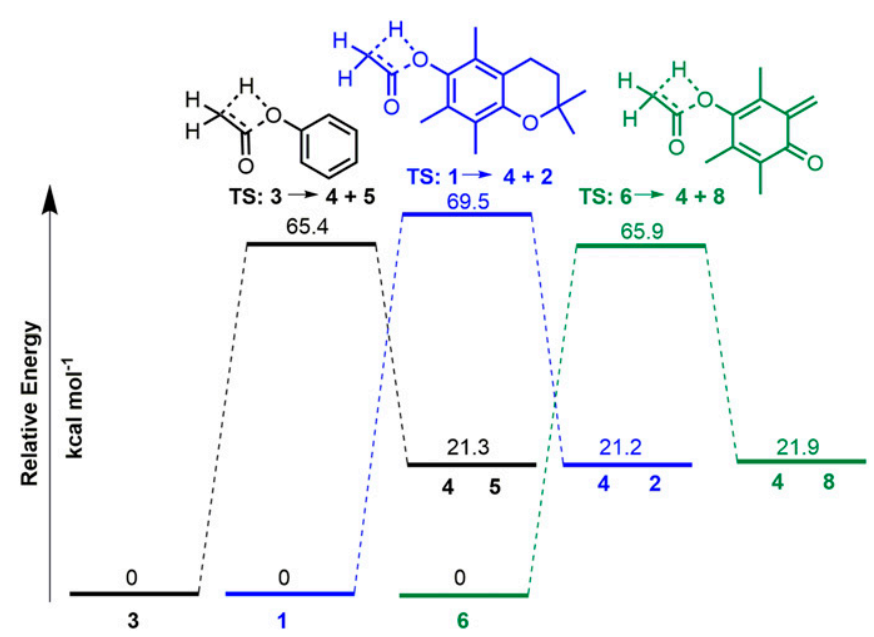

Fig. 4. Calculated energy profiles for the pyrolysis of the three aryl acetate substrates 1, 3, and 6 via concerted [1,3] hydrogen shift mechanism. Relative free energies ( $\mathrm{kcal} \mathrm{mol}^{-1}$ ) for starting materials, TS, and products formed for the pyrolysis of phenyl acetate, vitamin E acetate, and 6 leading to the elimination of ketene 4 . For details of calculation data see SI Appendix, Figs. S4-S6. Simplified structures used for calculation of 1 and 2 without $\mathrm{C}_{15} \mathrm{H}_{32}$ alkyl group. 


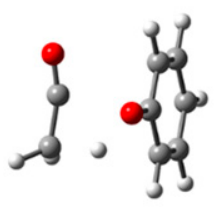

TS: $3 \rightarrow 4+5$

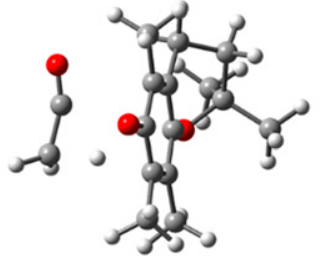

TS: $1 \rightarrow 4+2$

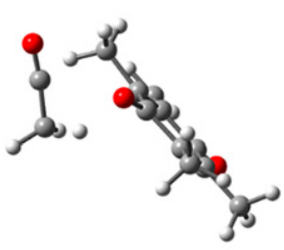

TS: $6 \rightarrow 4+8$
Fig. 5. Optimized geometries [M06-2X/6-311G(d,p) level] for the TS corresponding to the pyrolysis of phenyl acetate $\mathbf{3}$ (Left) and vitamin E acetate 1 (Middle) and 6 (Right), leading to the elimination of ketene. Simplified structures used for calculation of 1 and 2 without $\mathrm{C}_{15} \mathrm{H}_{32}$ alkyl group. For details of calculation data see SI Appendix, Figs. S4-S6.

$65.9 \mathrm{kcal} / \mathrm{mol}$, which is lower than $\mathbf{1}$ and comparable with $\mathbf{3}$ (Fig. 4, green energy profile). The optimized geometry of the four-membered cyclic TS for the unimolecular decomposition of $\mathbf{1}, \mathbf{3}$, and $\mathbf{6}$ showed similarity for each and that ortho-methyl substituents of $\mathbf{1}$ and $\mathbf{6}$ acetate did not impede ketene elimination (Fig. 5 and SI Appendix, Figs. S4-S6). Additionally, intrinsic reaction coordinate calculations confirmed the TS structures associated with the products and reactants along the minimum energy pathway.

As two pathways are operable for the elimination of ketene from 1, DFT calculations were carried out to determine if either one was more favorable. The competitive first steps of the two pathways are either loss of ketene from 1 forming 2 or loss of prist-1-ene 7 from 1 forming $\mathbf{6}$, from which subsequent elimination of ketene would occur (Fig. $3 B$ ). Conversion of 1 into $6+$ 7 is akin to the pyrolysis of a chroman ring. Chroman pyrolysis occurs through a retro Diels-Alder reaction to produce orthoquinone methide and ethane by $\mathrm{C}-\mathrm{C}$ and $\mathrm{C}-\mathrm{O}$ bond cleavage in the dihydropyran ring (21). Employing gas-phase M06-2X/6$311 \mathrm{G}(\mathrm{d}, \mathrm{p})$ calculations, the TS energy barrier for the formation of 6 from 1 was determined to be $58.8 \mathrm{kcal} / \mathrm{mol}$ (SI Appendix, Fig. S7). This value is lower than conversion of $\mathbf{1}$ into $\mathbf{4}+\mathbf{2}$ by 10.7 $\mathrm{kcal} / \mathrm{mol}$. As such, it seems probable that both ketene-producing pathways may be in operation, i.e., $1 \rightarrow 4+2$ and $1 \rightarrow 6 \rightarrow 4+8$ but that the latter is more favorable.

Experimental Analysis of Vaped 1. With experimentation and theoretical evidence for the elimination of ketene from $\mathbf{1}$, we felt compelled to directly investigate the effect, if any, on vaping vitamin $\mathrm{E}$ acetate. However, it should be noted that these experiments were not designed to exactly replicate a user's experience; rather, the goal was to determine the vaping pyrolysis effect on 1 as a single pure substance at the chemistry molecular level. Extrapolation of the exact relevance of these results to the direct cause of lung injury is beyond the scope of this preliminary report due to the diversity in vaping devices, mixtures, and their modes of use. As described in Methods, the isolated mixture of vaped 1 was collected and analyzed as either the total vaped mixture or following separation into its volatile (VC) and nonvolatile components (NVC). APCI-MS analysis was inconclusive, as spectra closely resembled that of pure 1, although it was suspected that changes may be masked by the fragmentation pattern of remaining $\mathbf{1}$ and the formation of hydrocarbon fragments that are not APCI-MS responsive (SI Appendix, Fig. S8). As such, NMR data were collected for the total vaped material and individually for the VC and NVC of the vaped mixture. Comparison of the ${ }^{1} \mathrm{H}$ NMR spectrum of the entire vaped material with that of pure 1 was revealing as it showed that significant chemical transformations had occurred. Numerous peaks with complex splitting patterns, not observed for vitamin E acetate, between 4.6 and 7.4 ppm were recorded in the vaped material and the spectral region between 0.8 and 2.1 ppm showed increased complexity (Fig. 6 and $S I$ Appendix, Fig. S9).

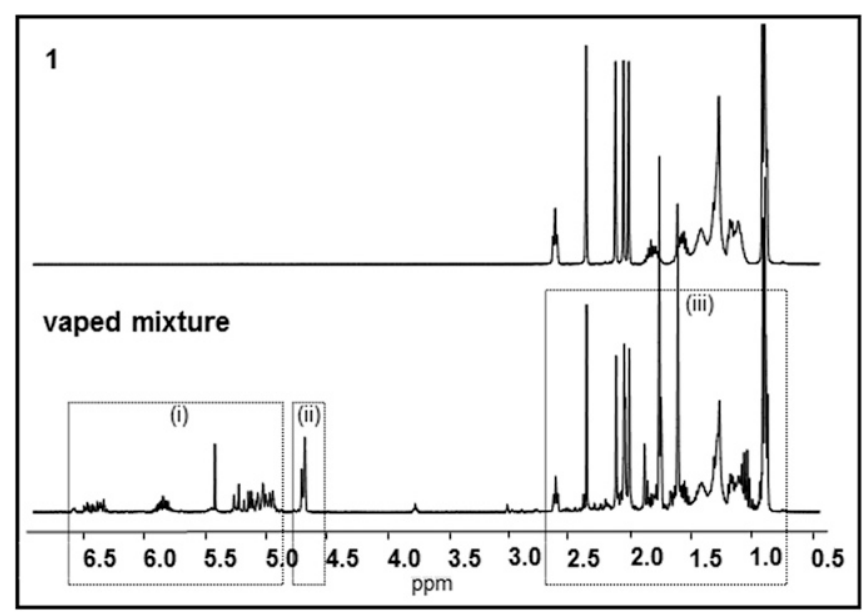

Fig. 6. (Top) ${ }^{1} \mathrm{H}$ NMR spectrum of pure 1. (Bottom) ${ }^{1} \mathrm{H}$ NMR spectrum of entire isolated vaped mixture from 1. For clarity the peak at $7.36 \mathrm{ppm}$ is not shown in cropped view, see SI Appendix, Fig. S9 for full spectra. Inset box (i) indicates VC; box (ii) indicates mixture of VC and NVC; box (iii) primarily NVC.

Separate ${ }^{1} \mathrm{H}$ NMR spectra were obtained for both NVC and VC. Close examination of the NVC spectrum and comparison with $\mathbf{1}$ and $\mathbf{2}$ provided important insights (Fig. 7 and SI Appendix, Fig. S10). This showed that NVC comprised vitamin E acetate 1 (key singlet peaks at 2.09, 2.03, $1.98 \mathrm{ppm}), 2,3,5,6$-tetramethylcyclohexa2,5-diene-1,4-dione, (duroquinone) 8 (key singlet peak at $2.01 \mathrm{ppm}$ ), and prist-1-ene 7 (key doublet peak at $4.68 \mathrm{ppm}$ ). The assignments of 7 and 8 were further confirmed by ${ }^{13} \mathrm{C}$ spectra, proton-carbon correlations using heteronuclear single quantum coherence spectroscopy, and heteronuclear multiple bond correlations (SI Appendix, Fig. S11). Comparison with a spectrum of pure 2 showed that, perhaps surprisingly, no vitamin E was contained in the mixture (key singlet peaks at 2.18, $2.13 \mathrm{ppm}$, two overlapping singlets) (Fig. 7). Integration of a methyl singlet of $\mathbf{1}$ versus that for duroquinone $\mathbf{8}$ gave an estimate of vape-induced pyrolysis between $15-20 \%$. This amount of pyrolytic conversion was consistent across six independent experiments. The formation of $\mathbf{8}$ was confirmed by high-performance liquid chromatography (HPLC) and gas chromatography (GC)-MS experiments (SI Appendix, Figs. S12 and S13).

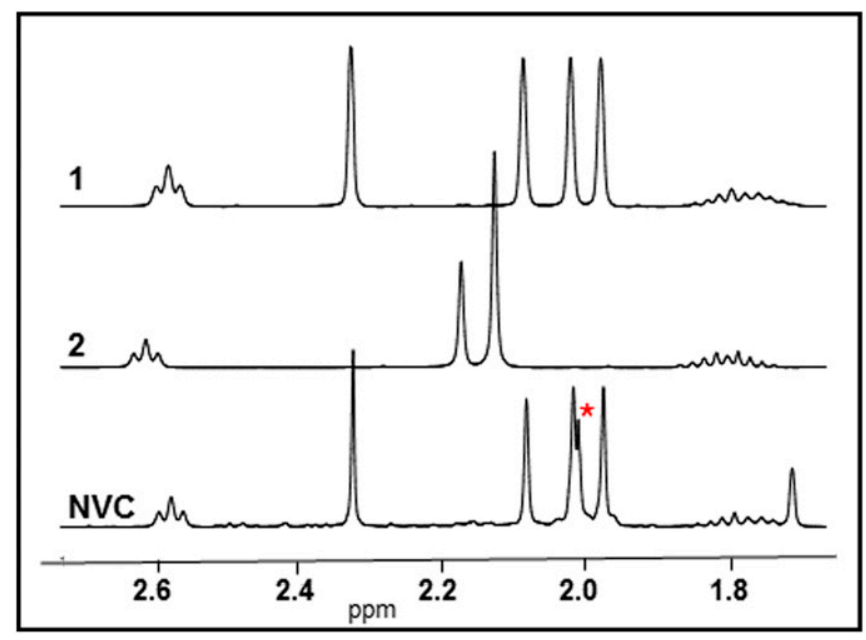

Fig. 7. Portion of the ${ }^{1} \mathrm{H}$ NMR spectrum of vitamin $\mathrm{E}$ acetate 1, vitamin $\mathrm{E} 2$ and the isolated NVC of vaped mixture. A red asterisk marks the aryl methyl signal for duroquinone 8 (full spectra in SI Appendix, Fig. S10). 


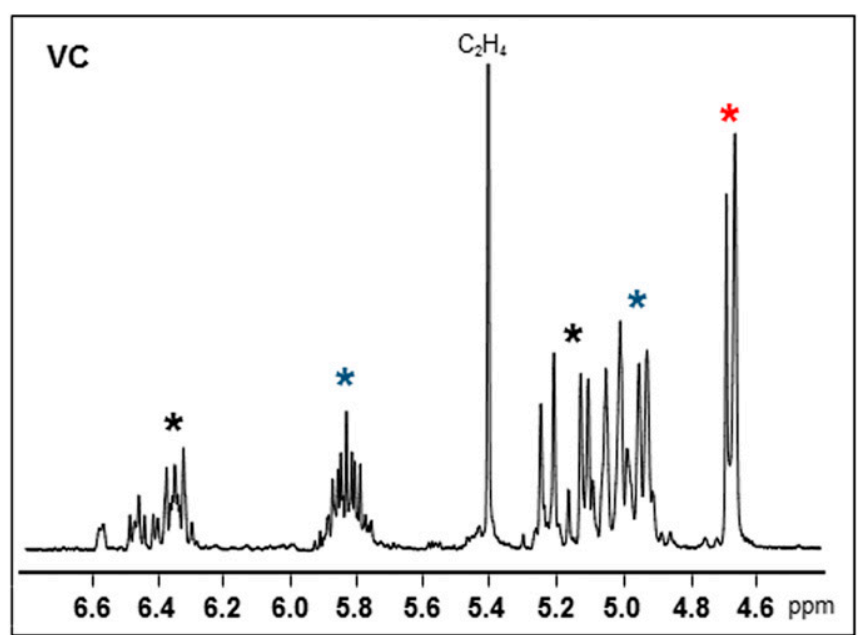

Fig. 8. Portion of the ${ }^{1} \mathrm{H}$ NMR spectrum of the isolated VC following vaping vitamin E acetate 1. See SI Appendix, Fig. S14 for full spectrum including benzene peak at 7.36 ppm. Red asterisk, 1-methyl-1-alkyl alkenes; blue asterisk, propene; black asterisk, butadiene.

NMR analysis identified the VC in the mixture as benzene (key singlet peak at $7.36 \mathrm{ppm}$ ), butadiene (key multiplet peak at $6.36 \mathrm{ppm}$ ), propene (key d,d,q peaks at $5.83 \mathrm{ppm}$ ), ethene (key singlet peak at $5.41 \mathrm{ppm}$ ), 2-methylprop-1-ene (key singlet peak at $4.66 \mathrm{ppm})$, and lower molecular weight 1-methyl-1-alkylalkenes (key doublet peak at 4.67 ppm) (Fig. 8). Trace amounts of tetrahydrofuran, formaldehyde, and short-chain aliphatic aldehydes were also observed (SI Appendix, Fig. S14). Propene was the most abundant volatile material with a three- to fourfold stoichiometric ratio greater than that of duroquinone 8. This indicates that upon release of prist-1-ene 7 from 1, it fragments into numerous propene units and the other identified alkenes. Trace aldehydes would be oxidation products of these alkenes and benzene a downstream byproduct from them.
The routes to forming the spectrum of compounds generated by the vape pyrolysis of $\mathbf{1}$ are illustrated in Fig. 9. In pathway A, ketene is released from 1 to produce vitamin $\mathrm{E}$ which undergoes $\mathrm{C}-\mathrm{C}$ and $\mathrm{C}-\mathrm{O}$ bond breaking of the dihydropyran ring to produce 8 and 7. Pathway $B$ generates the same mixture of end products but by a different sequence such that first the dihydropyran ring cleaves followed subsequently by loss of ketene from 6. Long-aliphatic-chained alkene 7 undergoes further decomposition to produce the lower molecular weight alkenes ethene, propene, butadiene, and aromatic benzene. Importantly, many of these alkenes and benzene are known carcinogenic constituents within tobacco smoke $(22,23)$ and elevated amounts of their oxidative metabolites have been found in a study of adolescent e-cigarette users (24). Both pathways produced duroquinone $\mathbf{8}$, which is an organic oxidant although insufficient data are currently available of its inhalation hazards (25). The high ketene reactivity prevented its NMR detection within the isolated complex volatile mixture. Cumulatively, theoretical DFT calculations, analytical APCI-MS, and experimental results point toward pathway $\mathrm{B}$ being the predominate route of pyrolysis under vaping conditions.

As direct isolation of ketene under low-temperature conditions proved challenging, chemical trapping experiments were next carried out to verify its formation. Benzylamine 9 was chosen as a representative amine nucleophile as the chemical shift of its methylene group (s, $3.85 \mathrm{ppm}$ ) appears in a spectral region devoid of peaks in the vape mixture (between 4.6 and $3.8 \mathrm{ppm}$ ). Experimentally, the vaped mixture of $\mathbf{1}$ was passed through a trap containing a solution of benzylamine in $\mathrm{CDCl}_{3}$ at room temperature. Subsequent NMR analysis clearly showed an additional doublet at $4.36 \mathrm{ppm}$ (not present in the vape mixture alone) which was consistent with an authentic sample of the acetylation benzylamide product 10 (Fig. 10 and SI Appendix, Figs. S15 and S16). Integration of the benzylamide methylene peak, from three independent experiments, with that of the methyl signal for $\mathbf{8}$ approximated that $30 \%$ of ketene produced had reacted with $\mathbf{9}$. The formation of $\mathbf{1 0}$ was confirmed by HPLC and GC-MS experiments (SI Appendix, Figs. S17 and S18).

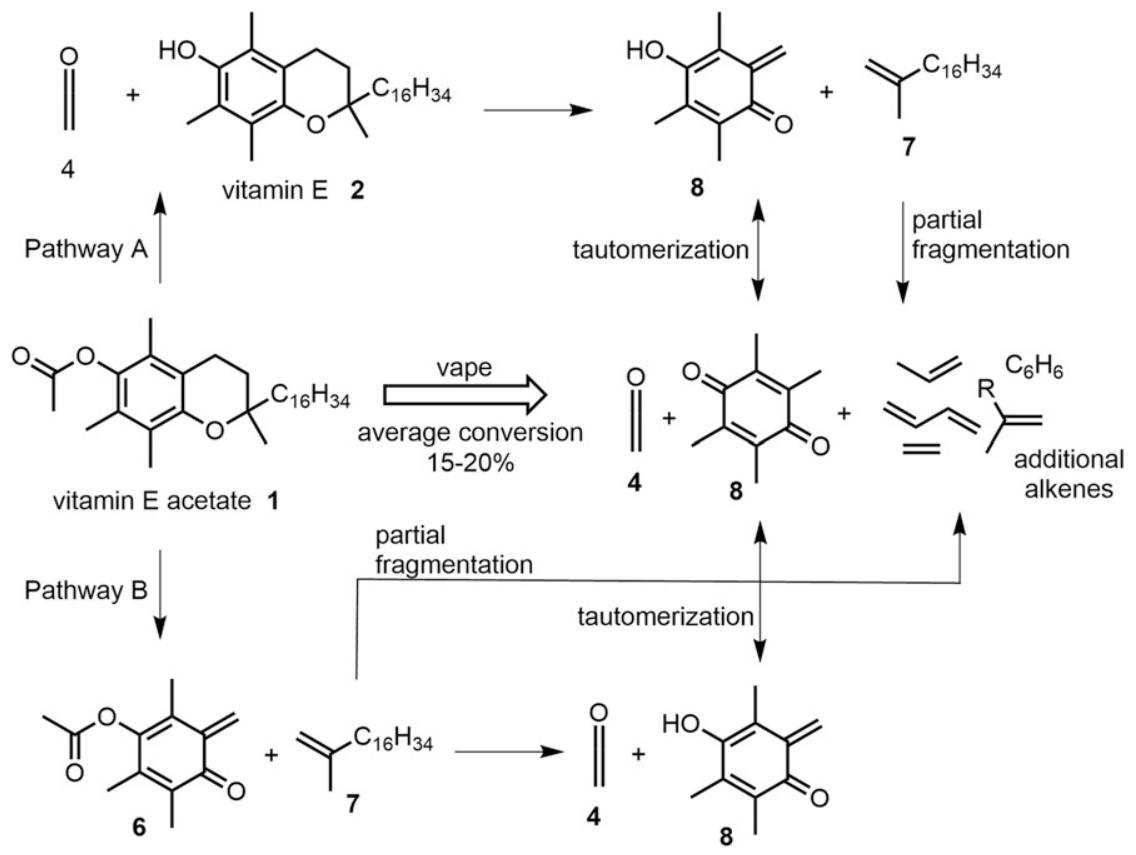

Fig. 9. Rationale of experimental and theoretical results from vape pyrolysis reactions of vitamin E acetate 1 . 

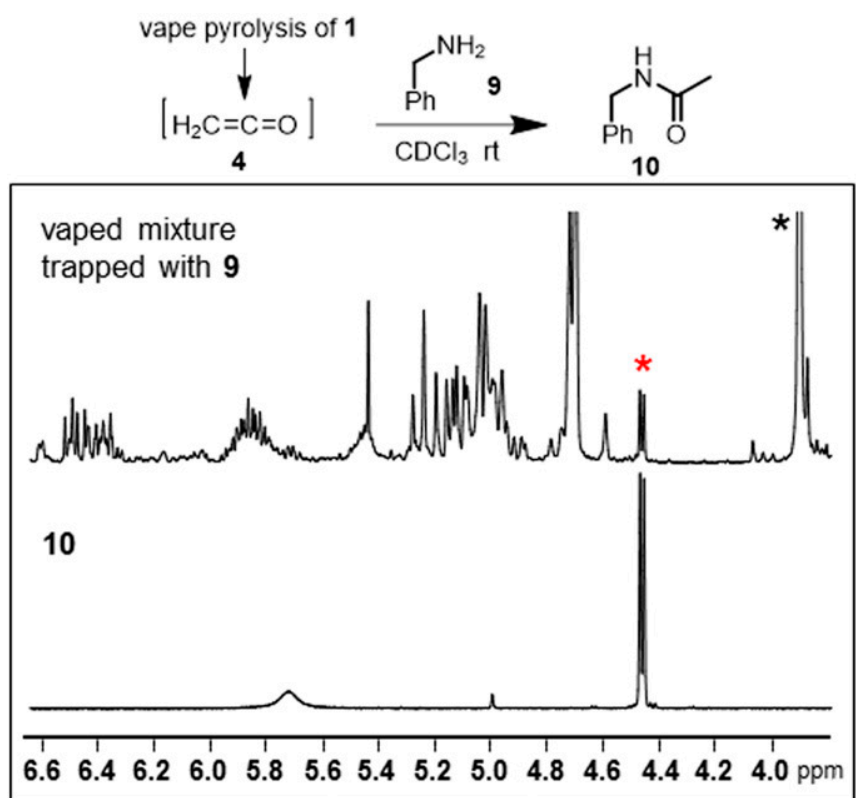

Fig. 10. Chemical trapping of vaped produced ketene with benzylamine 9 forming benzylamide 10 . Portion of the ${ }^{1} \mathrm{H}$ NMR spectra showing vape mixture from 1 isolated in $\mathrm{CDCl}_{3}$ containing 9 and an authentic sample of benzylamide 10. Black asterisk, methylene peak of 9; red asterisk, methylene peak of 10. See SI Appendix, Figs. S15 and S16 for full spectra.

The current worrying trend of increasing vaping-associated lung injuries is due to complex and multifaceted issues encompassing social, physical, biological, and medical sciences. When viewed from a physical science standpoint, medical complications from vaping a diverse set of substrates is perhaps not unexpected as the pyrolytic chemistry of single pure compounds is complex, so what occurs within ill-defined mixtures is a risky venture into the unknown. The temperatures obtainable within vaping devices places them in the category of a small-scale laboratory pyrolysis apparatus which if not used with precision and care can have unforeseen outcomes. In this article, we have highlighted the chemical basis for concern over vitamin E acetate, just one known component of vape mixtures. Our primary concern initially lay with the ability of the aryl acetate functional group to eliminate as ketene, although other reactive and known carcinogen (alkenes, benzene) are also produced for which the negative long-term effects are well recognized. Thermal activation of aryl acetates above their decomposition temperatures leads to the formation of highly toxic ketene, which if inhaled into the lungs, even in small quantities, can cause severe pulmonary injury. Evidence for ketene formation from vitamin $\mathrm{E}$ acetate was obtained from APCI-MS, DFT calculations, and trapping experiments. In closing, it is important to note that it is most likely that other aryl $O$-acetates would eliminate ketene in a similar manner to the two substrates investigated in this article. Additionally, published data on the pyrolysis of flavor ingredients and additives used in vape products verified the generation of a spectrum of known carcinogens (26). Considering the continuing evolving and large number of natural and synthetic substances used in recreational vaping and the unknown chemistries that may occur under vaping pyrolysis conditions, urgent research into this topic is now required. The most efficient approach would appear to be the development of pyrolysis prediction software, cross-referenced with toxicity data, allowing the rapid identification of individual compounds and compound mixtures that pose the most serious risks.

\section{Methods}

DL- $\alpha$-tocopherol acetate (vitamin E acetate), $( \pm)-\alpha$-tocopherol (vitamin $E)$, pheny acetate, duroquinone, benzylamine, and chloroform $\mathrm{d}_{1}$ were purchased from Sigma-Aldrich. Benzylamide was synthesized following a literature procedure (27). Vaping device (NEXUS P-1 mini) was purchased in a retail outlet in Dublin, Ireland. Vaping device (30-50 W, 129 A, $0.25 \Omega$ Kanthal coil) was used fully charged and at $50 \mathrm{~W}$ power setting. Mass spectra of each sample were recorded using an Advion Expression mass spectrometer, with each sample analyzed at a series of source voltages of $5,10,20$, and $30 \mathrm{eV}$. Other instrument parameters including capillary temperature: $250{ }^{\circ} \mathrm{C}$; capillary voltage $180 \mathrm{eV}$; source voltage span $30 \mathrm{eV}$; source gas temperature $350^{\circ} \mathrm{C}$; $\mathrm{APCl}$ corona discharge 5 were used consistently for all samples. MS solvent system of $\mathrm{MeOH} / \mathrm{IPA} / \mathrm{H}_{2} \mathrm{O} /$ $\mathrm{CHO}_{2} \mathrm{H}$ in a ratio of $80: 10: 10: 0.1$. Positive mode was superior to negative mode and was selected for use throughout the study. Positive-mode ESI mass spectra of vitamin E acetate were complicated by the appearance of significant amounts of sodium adducts which were not prevalent in the APCI spectra, as such APCI was selected as the preferred mode for analysis. NMR spectra were obtained on a $400-\mathrm{MHz}$ instrument in $\mathrm{CDCl}_{3}$. $\mathrm{HPLC}$ analysis
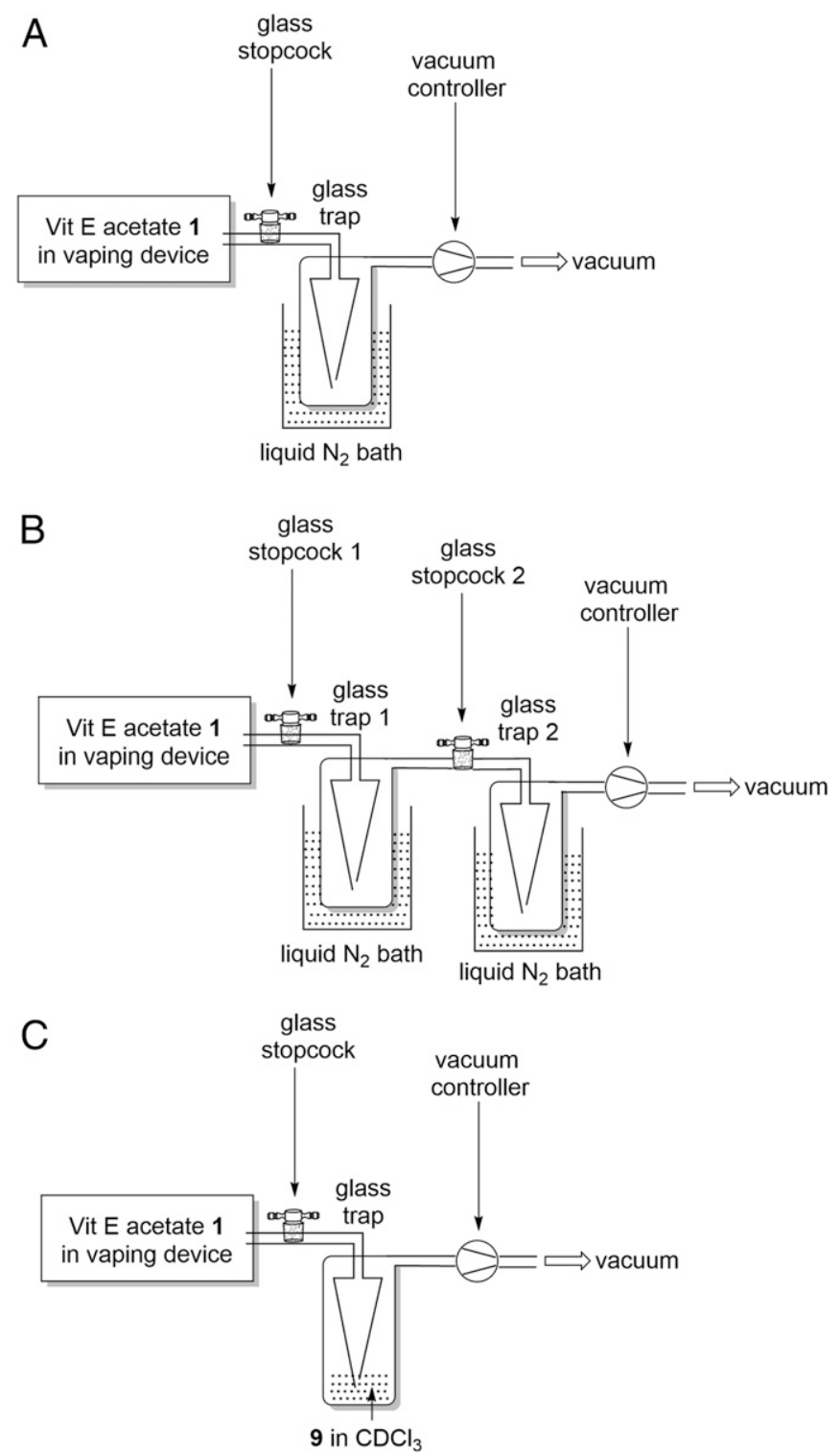

Fig. 11. Apparatus setup for trapping vaped products of vitamin $E$ acetate 1. Setup A: Apparatus for low-temperature trapping of all vaped material. Setup B: Apparatus for low-temperature trapping of all vaped material followed by separation of VC from NVC. Setup C: Apparatus for trapping of vape-produced ketene by benzylamine in $\mathrm{CDCl}_{3}$. 
used an Atlantis dC18 reverse-phase column $(5 \mu \mathrm{M}, 4.6 \times 250 \mathrm{~mm}$ with UV-vis detector at 254 and $220 \mathrm{~nm}$, mobile phase $A C N / \mathrm{H}_{2} \mathrm{O} 30: 70$ to $90: 10$ from 0.01-30 $\mathrm{min}$, flow rate $1 \mathrm{~mL} / \mathrm{min}$ ).

Apparatus for Vape Pyrolysis Trapping Experiments. Glass traps were purchased from Rettberg $\mathrm{GmbH}$, catalog number 137082015. Rubber tubing was used to connect vaping device to the glass trap 1, the glass traps together, and glass trap to the vacuum source. Low-form Dewar flasks (Sigma-Aldrich catalog number Z150398) were used for liquid nitrogen baths. Schematics of the apparatus configurations are shown in Fig. 11 and photographs showing the apparatus used are shown in SI Appendix, Fig. S19. The average weight of isolated vaped material was measured from three independent experiments at $2.4 \mathrm{mg}$ per puff.

Procedure for Vape Pyrolysis with Low-Temperature Trapping. Vaping experiments were conducted in a fumehood using the apparatus setup as shown in Fig. 11A. The vaping device containing 1 was connected via rubber tubing to the stopcock which in turn was connected to the glass trap, the outlet of which was connected by rubber tubing to the vacuum source. Once assembled the glass trap was placed into a liquid $\mathrm{N}_{2}$ bath for 2 min and vaping then commenced. The vaping device was turned on for $5 \mathrm{~s}$ with an airflow (65 $\mathrm{mL} / \mathrm{min}$ ) applied, generated by a vacuum, to draw the vapor (puff volume $35 \mathrm{~mL}$ ) into the trap. This was repeated 8 times at 30-s intervals and the airflow was stopped by closing the vacuum. To analyze the vaped material the trap was isolated from the vaping device by closing the stopcock, $\mathrm{CDCl}_{3}$ $(1.0 \mathrm{~mL})$ was added to the trap, the trap removed from the liquid $\mathrm{N}_{2}$ bath, and allowed to warm to room temperature. The $\mathrm{CDCl}_{3}$ was removed from the trap and immediately analyzed by NMR.

Procedure for Vape Pyrolysis with Low-Temperature Trapping and Separation of VC from NVC. All vaping experiments were conducted in a fumehood using the apparatus setup as shown in Fig. 11B. The vaping device containing 1 was connected via rubber tubing to stopcock 1 which was connected to glass trap 1. The outlet of glass trap 1 was connected to stopcock 2, which was connected to trap 2 which was connected by rubber tubing to the vacuum source. Once assembled, glass traps 1 and 2 were placed into individual liquid $\mathrm{N}_{2}$ baths for 2 min and vaping then commenced. The vaping device was turned on for $5 \mathrm{~s}$ with an airflow (65 $\mathrm{mL} / \mathrm{min}$ ) applied, generated by a vacuum, to draw the vapor (puff volume $35 \mathrm{~mL}$ ) into trap 1. This was repeated 8 times at 30 -s intervals, the airflow stopped by closing the vacuum, and stopcock 1 closed to

1. H. Ledford, Scientists chase cause of mysterious vaping illness as death toll rises. Nature 574, 303-304 (2019).

2. M. C. Madison et al., Electronic cigarettes disrupt lung lipid homeostasis and innate immunity independent of nicotine. J. Clin. Invest. 129, 4290-4304 (2019).

3. B. C. Blount et al.; Lung Injury Response Laboratory Working Group, Vitamin E acetate in bronchoalveolar-lavage fluid associated with EVALI. N. Engl. J. Med. 382, 697-705 (2020).

4. M. A. Keen, I. Hassan, Vitamin E in dermatology. Indian Dermatol. Online J. 7, 311 315 (2016).

5. J. E. Layden et al., Pulmonary illness related to E-cigarette use in Illinois and Wisconsin-Preliminary report. N. Engl. J. Med., 10.1056/NEJMoa1911614 (2019).

6. S. D. Maddock et al., Pulmonary lipid-laden macrophages and vaping. N. Engl. J. Med. 381, 1488-1489 (2019)

7. T. S. Henry, J. P. Kanne, S. J. Kligerman, Imaging of vaping-associated lung disease. $N$ Engl. J. Med. 381, 1486-1487 (2019).

8. Y. M. Butt et al., Pathology of vaping-associated lung injury. N. Engl. J. Med. 381 1780-1781 (2019).

9. W. Chen et al., Measurement of heating coil temperature for e-cigarettes with a "topcoil" clearomizer. PLoS One 13, e0195925 (2018)

10. O. Geiss, I. Bianchi, J. Barrero-Moreno, Correlation of volatile carbonyl yields emitted by e-cigarettes with the temperature of the heating coil and the perceived sensorial quality of the generated vapours. Int. J. Hyg. Environ. Health 219, 268-277 (2016).

11. C. D. Hurd, F. H. Blunck, The pyrolysis of esters. J. Am. Chem. Soc. 60, 2419-2425 (1938).

12. H. Nakata, A. Tatematsu, Mechanism of mass spectral ketene elimination from phenyl acetates. Org. Mass Spectrom. 5, 1343-1344 (1971).

13. R. Miller, C. Abaecherli, A. Said, B. Jackson, "Ketenes" in Ullmann's Encyclopedia of Industrial Chemistry (Wiley-VCH Verlag GmbH \& Co. KGaA, Weinheim, Germany, 2012), vol. 20, pp. 171-183.

14. National Institute for Occupational Safety and Health (NIOSH), Ketene. https://www. cdc.gov/niosh/idlh/463514.html. Accessed 24 February 2020. isolate the traps from the vaping device. Trap 1 was removed from its liquid $\mathrm{N}_{2}$ bath and allowed to warm to room temperature. Once trap 1 reached room temperature, it was isolated from trap 2 by closing stopcock 2 . Following isolation of traps 1 and 2 from each other, $\mathrm{CDCl}_{3}(1.0 \mathrm{~mL})$ was added to each trap. Trap 2 was removed from its liquid $\mathrm{N}_{2}$ bath and allowed to warm to room temperature. The $\mathrm{CDCl}_{3}$ was removed from both traps and immediately analyzed by NMR. Spiking vape samples with pure benzene and duroquinone confirmed their assignments. The formation of $\mathbf{8}$ was confirmed by HPLC, GCMS experiments, and accurate mass measurement.

Procedure for Trapping Vape Pyrolysis-Produced Ketene 4 with Benzylamine 9. All vaping experiments were conducted in a fumehood using the apparatus setup as shown in Fig. 11C. The vaping device containing 1 was connected via rubber tubing to the stopcock which in turn was connected to the glass trap, the outlet of which was connected by rubber tubing to the vacuum source. Benzylamine $9(0.02 \mathrm{~mL}, 0.183 \mathrm{mmol})$ in $\mathrm{CDCl}_{3}(2.0 \mathrm{~mL})$ was added into the glass trap. The vaping device was turned on for $5 \mathrm{~s}$ with an airflow (65 mL/min) applied, generated by a vacuum, to draw the vapor (puff volume $35 \mathrm{~mL}$ ) into the trap. This was repeated 30 times at 30-s intervals and the airflow was stopped by closing the vacuum. The $\mathrm{CDCl}_{3}$ was removed from the trap and immediately analyzed by NMR and reverse-phase HPLC (Atlantis dC18 reverse-phase column, mobile-phase $A C N / \mathrm{H}_{2} \mathrm{O} 30: 70$ to $90: 10$ from 0.01-30 min, flow rate $1 \mathrm{~mL} / \mathrm{min}$ ). Benzylamide 10 was identified in vape mixture NMR by a doublet peak at $4.36 \mathrm{ppm}$ and confirmed by spiking the vape sample with pure 10. HPLC retention time for benzylamide in the vape mixture was $5.0 \mathrm{~min}$, which was confirmed by spiking the vape mixture with an authentic sample of 10 . The formation of 10 was confirmed by GC-MS experiments and accurate mass measurement. Excess of benzylamine was removed by aqueous acid extraction prior to GC-MS analysis. A control experiment showed no formation of benzylamide $\mathbf{1 0}$ following mixing 1 and 9 in $\mathrm{CDCl}_{3}$ for $24 \mathrm{~h}$.

Data and Materials Availability. All data are available in the main text or SI Appendix. Raw data files are available from the corresponding author upon request.

ACKNOWLEDGMENTS. D.W. acknowledges the Synthesis and Solid State Pharmaceutical Centre for postdoctoral funding support. Thanks to the Irish Centre for High-End Computing and Dr. G. Sanchez for use of computational hardware and software resources. Thanks to Emmet Campion (RCSI) for assistance with mass spectrometry and NMR experiments.

15. R. M. Mendenhall, H. E. Stokinger, Tolerance and cross-tolerance development to atmospheric pollutants ketene and ozone. J. Appl. Physiol. 14, 923-926 (1959).

16. L. S. Hardison, Jr, E. Wright, A. F. Pizon, Phosgene exposure: A case of accidental industrial exposure. J. Med. Toxicol. 10, 51-56 (2014).

17. J. F. Treon et al., Physiologic response of animals exposed to air-borne ketene. J. Ind. Hyg. Toxicol. 31, 209-219 (1949).

18. M. J. Frisch et al., Gaussian 09 (Revision A.1, Gaussian, Inc., Wallingford, CT, 2009)

19. R. Taylor, The mechanism of thermal eliminations, part 25. Arrhenius data for pyrolysis of isochroman-3-one, benzyl methyl ether, 2-hydroxyethylbenzene, phenyl acetate, and 3,4-dihydro-2H-pyran. J. Chem. Soc. Perkin Trans. 2, 183-189 (1988)

20. E. Ghibaudi, A. J. Colussi, Very low pressure pyrolysis of phenyl acetate. Int. J. Chem. Kinet. 16, 1575-1583 (1984)

21. J. Bland, G. da Silva, A detailed chemical kinetic model for pyrolysis of the lignin model compound chroman. AIMS Environ. Sci. 1, 12-25 (2014).

22. K. A. Persson, S. Berg, M. Törnqvist, G. P. Scalia-Tomba, L. Ehrenberg, Note on ethene and other low-molecular weight hydrocarbons in environmental tobacco smoke. Acta Chem. Scand. B 42, 690-696 (1988).

23. K. G. Darrall, J. A. Figgins, R. D. Brown, G. F. Phillips, Determination of benzene and associated volatile compounds in mainstream cigarette smoke. Analyst (Lond.) 123, 1095-1101 (1998).

24. M. L. Rubinstein, K. Delucchi, N. L. Benowitz, D. E. Ramo, Adolescent exposure to toxic volatile organic chemicals from e-cigarettes. Pediatrics 141, e20173557 (2018).

25. A. G. Siraki, T. S. Chan, P. J. O'Brien, Application of quantitative structure-toxicity relationships for the comparison of the cytotoxicity of 14 p-benzoquinone congeners in primary cultured rat hepatocytes versus PC12 cells. Toxicol. Sci. 81, 148-159 (2004).

26. Zs. Czégény et al., Thermal behavior of selected flavour ingredients and additives under simulated cigarette combustion and tobacco heating conditions. J. Anal. Appl. Pyrolysis 121, 990-204 (2016).

27. X. Wang et al., Synthesis and biological evaluation of phenoxyacetic acid derivatives as novel free fatty acid receptor 1 agonists. Bioorg. Med. Chem. 23, 132-140 (2015). 